\title{
Differences in social-space-time behaviour of two red deer herds (Cervus elaphus)
}

\author{
Benjamin Gillich ${ }^{1,2}\left(\mathbb{D} \cdot\right.$ Frank-Uwe Michler $^{1} \cdot$ Caroline Stolter $^{2} \cdot$ Siegfried Rieger $^{1}$
}

Received: 16 July 2020 / Revised: 4 June 2021 / Accepted: 18 June 2021 / Published online: 3 July 2021

(C) The Author(s) 2021

\begin{abstract}
Social-space-time-behaviour has developed very differently (e.g. a, loner, a herd, a pack) in the animal kingdom and depends on many different factors, like food availability, competition, predator avoidance or disturbances. It is known, that red deer are differently distributed in human disturbed areas compared to areas with less anthropogenic influences. But knowledge about the potential influence of human presence on social associations and interactions is rare, albeit differences may result in changing impacts on the environment, such as habitat utilization and feeding damage. Therefore, we investigated differences in the space use and social association of red deer. We studied two radio-collared herds of non-migratory populations in two study areas, which were comparable in landscape structure and vegetation structure, but differed in accessibility for visitors and the extent of their presence. Between the two study sites we compared the home range size, the differences in the extent of home range overlap within each study site and the space-time association (Jacobs Index) of individuals. Additionally, we present data on seasonal variations of home range sizes and social association all year round. In order to compare human activity in the study sites, we used the data from our long-term camera trap monitoring. The herd in the area with more human activity had significantly smaller home ranges and had greater year-round social associations in almost all seasons, except summer. We assume that smaller home ranges and higher association between animals may result in a higher feeding pressure on plants and a patchier utilization in areas with higher disturbances.
\end{abstract}

Keywords Social associations $\cdot$ Social behaviour $\cdot$ Space-time-behaviour $\cdot$ Grouping behaviour

\section{Introduction}

There are many kinds of social association and grouping patterns in the animal kingdom which can occur at all sizes and across a range of temporal stability (Allee 1931). Animal association can be related to kinship, as well as an adaption to external environmental influences and can help accomplish a wide variety of tasks. For example, grouping of predators can facilitate an increase in prey body mass and hunting success (MacNulty et al. 2014). For prey, group formation can decrease predation risk (Krause and Godin 1995;

Benjamin Gillich

benjamin.gillich@hnee.de

1 Department of Wildlife Biology, Wildlife Management and Hunting Practice, Eberswalde University for Sustainable Development, Alfred-Möller-Straße 1, 16225 Eberswalde, Germany

2 Institute of Zoology, University of Hamburg, Martin-Luther-King Platz 3, 20146 Hamburg, Germany
Krause et al. 1998). Lazarus (1979) found that larger groups detect attacks sooner than smaller ones. Thus, increased grouping pays off in insecure areas (Hirth 1977).

It is known that the social behaviour of a herd, or an individual deer, depend on the species. For example, the moose (Alces alces) are solitary, while the roe deer (Capreolus capreolus) live alone only temporarily. Alternatively, the white-tailed deer (Odocoileus virginianus) live in small matriarchal family groups, which vary in size throughout the year (Nelson and Mech 1981). The red deer behave similarly. Their herds are composed of a small kindred family group (Clutton-Brock et al. 1982), led by a dominant, mature doe (Darling 1937; Hall 1983). Furthermore, the grouping of deer is subject to seasonal variations. During the breeding season, in the spring, female deer are more solitary, but they regroup for the winter (Hirth 1977; Nelson and Mech 1981). On the other hand, male deer separate from their herds during the rut in the autumn but are closely associated with one another during the spring and summer (Nelson and Mech 1981). 
Differences in space use are, as well as differences in social associations, a good indicator of various environmental influences affecting the animals. Home range size is a fundamental measure of space use by the animals. Variation in home range sizes in deer are attributed to many different factors like sex and age (Cederlund and Sand 1994), seasons and food availability (Kamler et al. 2008; Saïd and Servanty 2005; Reinecke et al. 2014) and cover (Tufto et al. 1996). Additionally, anthropogenic influences are known to affect home range sizes of deer. In urban environments, with more human presence, deer reduced their home range sizes compared to deer in a rural environment (Grund et al. 2002). Jerina (2012) showed that home range sizes of deer increased with increasing distance to roads. Furthermore, direct human disturbances, such as logging activity, can also affect home range size of deer in a negative way (Edge et al. 1985).

Unlike how Berger (2007) described unhunted populations of deer using humans as a shield against predators, red deer in Germany are traditionally hunted, and therefore most likely particularly sensitive to human disturbances (Stankowich 2008). This may lead to adaptations in their behaviour, avoidance of disturbed areas, or adjustments of their home ranges (Seip et al. 2007; Jayakody et al. 2008; Sibbald 2011; Lone et al. 2015; Picardi et al. 2018; Scholten et al. 2018). The avoidance can even lead to the utilization of habitats with sub-optimal conditions, e.g. lower carrying capacity or lesser quality diet (Jayakody et al. 2008); this may result in negative consequences for animals' fitness. But so far, little is known about human activities influencing the social associations of deer in a herd, especially of free-living animals. Jayakody et al. (2008) observed that red deer respond to human disturbances with higher vigilance and higher association within the herd. Therefore, we expected red deer to be more associated within the herd in response to a higher level of human activities. This should result in smaller home ranges, a higher spatial overlap and the simultaneous use of the same home range area throughout the year.

Since the space-time behavior of animals is influenced not only by changing environmental conditions such as growing season and weather conditions, but also by incidents such as the rutting time and the breeding season, the association may not be constant throughout the year (Bertrand et al. 1996). According to the resource dispersion hypothesis, the size of the deer's home range should be affected by seasonal variations; this is due to changes in the availability and quality of food (McDonald 1983). This seasonal pattern should not vary much between herds, meaning different herds should experience the same pattern of seasonal growth or decline of their home range size in different areas during the course of the year.

In order to study the changes in space use and social associations inside a herd, we chose two study sites with similar weather conditions, plant/animal composition, landscape structure and military usage history, but with different levels of human activity. Overall, we wanted to know if the space use and social association of red deer varies between two study areas of different levels of human activity. We hypothesized that activities influence the spatial and temporal association of herds. We predicted that with a higher level of human activity, there would be an increase in the herd's social association together with smaller home range sizes of the individual deer. Specifically, we investigated the difference between the areas in (a) home range size, (b) spatial overlap of home ranges and (c) space-time associations.

Furthermore, we present data on the seasonal variation in home range sizes and association level throughout one year.

\section{Materials and methods}

\section{Study area}

Red deer were studied at two sites (approximately $45 \mathrm{~km}$ apart) in Saxony-Anhalt, Germany, called "Glücksburger Heide" (GH) (N 51.872723, E 12.985387, 2595 ha, 85 m a.s.l.) and "Oranienbaumer Heide" (OH) (N 51.774603, E 12.364772, 2114 ha, $70 \mathrm{~m}$ a.s.l.). These areas were very similar in climate (yearly precipitation of $500-550 \mathrm{~mm}$, including very rare snowfall and a mean annual temperature of 9.1-9.2 ${ }^{\circ} \mathrm{C}$ ), in type of landscape and in military usage history. Both sites were used multiple times as military training areas for different armies. Consequently, the vegetation structure and cover were similar. Large parts of both study areas were characterized by heather- and grassland habitats and early successional stages of forest. The main tree species in both areas were birches (Betula pendula), pines (Pinus sylvestris) and aspen (Populus tremula). Dominant ground cover vegetation included common heather (Calluna vulgaris), bushgrass (Calamagrostis epigejos) and common broom (Cytisus scoparius) (Jentzsch and Reichhoff 2013). Forests and extensive farming areas surrounded both areas. We used Landsat data for the calculation of the vegetation index NDVI. For this, we grouped our investigation sites $(\mathrm{OH}$ and $\mathrm{GH}$ ) into different vegetation classes: Young deciduous trees, old deciduous stands, young coniferous trees, old coniferous stands, heath and open dry grassland, agricultural fields, meadows, ways and water. The results of the NDVI index $(\mathrm{GH}=0.69291 ; \mathrm{OH}=0.69204)$ were supporting the similarity of both habitats. Besides, red deer, roe deer and wild boar (Sus scrofa) were also present in $\mathrm{GH}$ and $\mathrm{OH}$. At the time of the study (winter 2016-winter 2017), there was also one wolf pack (Canis lupus) in each study site (Landesamt für Umweltschutz SachsenAnhalt and Wolfskompentenzzentrum Iden 2017). The same hunting concept was implemented in both study sites. It included up to two driven hunts with human drivers and dogs, as well as interval hide hunting, 
where a group of hunters used high seats to hunt at the same time, in May and September-December per annum. There was no supplementary food for red deer provided.

The main differences between both areas are:

a) Only in $\mathrm{OH}$ was there a large coherent fenced grazing area (800 hectares), where cattle and horses are kept all year round. These grazing animals and the approx. 30-km-long fence were inspected daily by the keeper, which results in a daily human presence in the area. Furthermore, vegetation needed to be cleared from the fence twice a year. However, red deer could pass the fence and roam freely through the complete study site (Gillich et al. 2016).

b) Most of the GH area was banned from public use and the core area is closed to everyone, because of the former military use and the associated duds. Therefore, the game is rather undisturbed. However, there were two public gravel paths in GH; in contrast, there were several popular public hiking paths in $\mathrm{OH}$, making large parts of the research area available for daily use by bikers, hikers, and for other recreational activities.

c) The closest property to GH was a village about one kilometer to the east with 289 inhabitants. Approximately $4.5 \mathrm{~km}$ to the south of GH was a small town with approximately 14,000 inhabitants. The closest property to the $\mathrm{OH}$ was a small town $200 \mathrm{~m}$ away with approximately 9000 inhabitants to the northeast. Eight kilometers to the west of $\mathrm{OH}$ was a town with over 88,000 inhabitants.

This was also confirmed by the district forester of the federal forestry (T. Kupitz, former district forester of both study sites, pers. comm. 2016).

\section{Data collection}

In GH in January 2015, we caught a herd of six female red deer: four adults and one sub-adults and one calf. In $\mathrm{OH}$, in January 2016, we caught a herd of five deer: three female adults, one female sub-adult and one male calf. To catch the deer, we used a 500- $\mathrm{m}^{2}$, manually triggered drop-net capturing system. Sugar beets were left under the nets to bait the animals. After capturing the animals, they were immediately immobilized with a mix of ketamine and xylazine. While under anesthesia, the animals were equipped with ear-tags (from TypiFix ${ }^{\mathrm{TM}}$ and Dalton $\mathrm{GmbH}$ ) and GPS-GSM-collars (models Pro Light and GPS PLUS both from Vectronic Aerospace $\mathrm{GmbH}$ ). Every $2 \mathrm{~h}$, the collars simultaneously determined a GPS position and transmitted it via GSM (Global System for Mobile) to our server. The investigation period lasted from the 20th of March 2016 to the 20th of March 2017.

Red deer calves are normally born in May and June and are nursed for approximately up to 6 months by the mother (Clutton-Brook et al. 1982). One year later, calves are growing into sub-adults for another year, before they become adults. This meant that at the beginning of the investigation period all collared deer in $\mathrm{GH}$ were adults and in $\mathrm{OH}$ too, besides one calf that turned over the year into a sub-adult deer. It is known that calves are normally strongly associated with their mother in the first year. After the first year, the association frequency between mothers and their offspring steadily decline. This trend also depends on the sex of the offspring (females are closer associated to their mother than males) and if the mother becomes pregnant again (a following pregnancy of the mother and a newborn calf results in a lower association with the older offspring) (CluttonBrook et al. 1982). Due to the fatality of one female adult deer (ID24 fell into an old well) in $\mathrm{OH}$, one individual was missing in the analysis for autumn and winter. For the data analysis, we only used the GPS positions that came from four or more satellites to guarantee highly precise positions. For a more detailed investigation, we divided the observation period of one year into four seasons, namely spring (March to May with $\mathrm{GH}: \mathrm{n}=4203 ; \mathrm{OH}: \mathrm{n}=6721$ positions of 10 female and 1 male deer), summer (June to August with GH: $\mathrm{n}=4218$; OH: $\mathrm{n}=6877$ positions of 10 female and 1 male deer), autumn (September to November with GH: $n=6032$; $\mathrm{OH}: \mathrm{n}=6365$ positions of 9 female and 1 male deer) and winter (December to February with $\mathrm{GH}: \mathrm{n}=5072$; $\mathrm{OH}$ : $\mathrm{n}=4375$ positions of 9 female and 1 male deer).

To underline the statement of the federal forestry, we counted human activity in both study sites. We used data from our systematic long-term camera trap wildlife monitoring from 2014 to 2019 in both study sites. For comparison, we used a total of six camera traps (black flash camera traps from Reconyx and Browning); three camera traps were installed at similar gravel paths in each site. Before we deleted all person-related pictures, we counted human activity, e.g. hikers, cyclists or cars. To compare both areas, we used $n=1457$ days of camera trapping in $\mathrm{GH}$ and $n=572$ days in $\mathrm{OH}$. Due to theft and damage to the property, the number of trapping days deviated between the areas. In GH, we detected 141 events of human activity during 1457 observation days (mean $=0.10$, std.dev $=0.32$ per day, $\min =0, \max =2$ per day). In OH, we found 361 events of human presence over 572-day period (mean $=0.63$, std. dev. $=0.89, \min =0, \max =8$, per day). Although we had 2.5 times more observation days in $\mathrm{GH}$ compared to $\mathrm{OH}$, the human presence was 2.6 times higher in $\mathrm{OH}$. According to this, the Mann-Whitney U test revealed significant differences in human presence between $\mathrm{OH}$ and $\mathrm{GH}(\mathrm{Z}=18.78$; $\mathrm{p} \leq 0.001 ; \mathrm{n}=2029$ ).

\section{Data analysis and statistics}

We used the software Ranges 9 version 1.8 (Kenward et al. 2014) for calculating space use (home range size), overlap of home range and space-time associations. We first 
calculated home ranges with 95\% fixed kernel (Silverman 1986; Worton 1989; Signer and Balkenhol 2015) for each deer in all seasons. To test for differences in seasonal home range sizes between the two herds, we used the independent samples t-test. Additionally, we tested for differences in seasonal home range sizes between the seasons with one-way analysis of variance (one way ANOVA). Both tests were performed in SPSS v.17 (SPSS Inc. 2008).

For the analysis of the home range overlap, we calculated the percentage of overlapping home range between each marked animal (MacDonald 1983; Doncaster 1990; Kenward 2001) for both herds and for all seasons. Moreover, we investigated the potential simultaneous use of the same area as a measurement for social bonds (space-time-association-analysis, Dunn 1979; Kenward 2001). To quantify this behaviour, we used the Jacob's index (Kenward 2001), as the method is recognized for this purpose (Kaulhala and Holmala 2006; Michler 2016).

We used simultaneous locations (recorded within a time buffer of $3 \mathrm{~min}$ ) for each dyad of animals to analyze their temporal association (Minta 1992). The association is calculated using the average distance of their simultaneous localizations ( $D_{O}$, observed distance) and the average distance of all recorded localizations of one animal (within the observation period) to all localizations of the second animal ( $D_{R}$, randomized distance). If there are $\mathrm{n}$ pairs of locations from one animal at the moment $\mathrm{i}\left(\mathrm{x}_{1 \mathrm{i}}, \mathrm{y}_{1 \mathrm{i}}\right)$ and animal two at the moment $\mathrm{i}\left(\mathrm{x}_{2 \mathrm{i}}, \mathrm{y}_{2 \mathrm{i}}\right)$ for each dyad, the observed mean distance between them is.

$$
D_{O}=\frac{1}{n} \sum_{i=1}^{n} \sqrt{\left(x_{1 i}-x_{2 i}\right)^{2}+\left(y_{1 i}-y_{2 i}\right)^{2}}(\mathrm{n}=\text { number }
$$

of simultaneous localizations of animal 1 and animal 2), which can be compared with the expected mean distance from animal one at the moment $\left(\mathrm{x}_{1 \mathrm{i}}, \mathrm{y}_{1 \mathrm{i}}\right)$ to all other localizations of animal two at the moment $\mathrm{j}\left(\mathrm{x}_{2 \mathrm{j}}, \mathrm{y}_{2 \mathrm{j}}\right)$,

$$
D_{R}=\frac{1}{n^{2}} \sum_{i=1}^{n} \sum_{j=1}^{n} \sqrt{\left(x_{1 i}-x_{2 j}\right)^{2}+\left(y_{1 i}-y_{2 j}\right)^{2}}
$$

that is obtained by randomizing all possible pairs of locations at which the animals were detected (Kenward et al. 2001). The Jacob's index $\left(J_{X}\right)$ is obtained by equation,

$$
J_{X}=\frac{D_{R}-D_{O}}{D_{R}+D_{O}} \text {. }
$$

The Jacob's index ranges from one to negative one, where negative one is a measure of maximum avoidance and plus one is a measure of maximum attraction. To compare the percentage overlap and the Jacob's index per season $(\mathrm{GH}$ : $\mathrm{n}=6$; $\mathrm{OH}: \mathrm{n}=5$ or 4 ), we built matrices with the values from the percentage overlap and the Jacob's index for each unique animal-season (Croft et al. 2008). The matrices were tested for significant differences using one-way PERMANOVA in the statistic program Past 3.14 (Hammer et al. 2001). The one-way PERMANOVA is a permutations test, which runs 9999 permutations as a standard.

Furthermore, we used the statistic software R 3.4.0 (R Core Team 2013) with the package igraph 1.0.1 (Csardi and
Nepusz 2006) to illustrate the Jacob's index as a network for the two herds for different seasons. The lines between the individuals in each herd represent their mutual association. The higher the values for the Jacob's index, the darker and wider the lines between individuals are.

\section{Results}

\section{Home range size}

On average, the home range size in GH (low human activity) was significantly larger than in $\mathrm{OH}$ (higher human activity) with 1582 hectares (std.dev $=175$ ) and 415 hectares (std.dev $=119$ ), respectively. This differentiation was valid throughout the entire study period of one year (Table 1). The largest home range sizes for both sites were recorded in autumn. At this time, the home range size in $\mathrm{GH}$ was more than three times greater than that in $\mathrm{OH}$. Conversely, the smallest home range sizes were recorded in different seasons for $\mathrm{OH}$ and $\mathrm{GH}$. In $\mathrm{GH}$, the home range was smallest in the summer with a size of 966 hectares, whereas in $\mathrm{OH}$, the size was the smallest in the spring with 235 hectares. Hence, we found a slightly different seasonal dependent pattern in the home range sizes for each of our study sites. Furthermore, we did not detect any significant differences in seasonal home range sizes in $\mathrm{OH}$, whereas we found one significant difference between the seasons spring and winter in GH (Table 2).

Table 1 Independent samples t-test to determine differences in home range sizes in hectares (95\% fixed kernel) for the four seasons and the whole investigation period (20 March 2016 to 20 March 2017) between the "Glücksburger Heide" $(\mathrm{GH})$ and the "Oranienbaumer Heide" $(\mathrm{OH})$

\begin{tabular}{lccccc}
\hline $\begin{array}{l}\text { Time period/ } \\
\text { study area }\end{array}$ & $\mathrm{n}$ & $M V$ & $S D$ & $T$ & $P$ \\
\hline \multicolumn{5}{l}{ Whole investigation period } \\
GH & 6 & 1582 & 175 & 12.62 & $\leq 0.001$ \\
OH & 5 & 415 & 119 & & \\
Spring & & & & & \\
GH & 6 & 1481 & 137 & 18.20 & $\leq 0.001$ \\
OH & 5 & 237 & 28 & & \\
Summer & & & & & \\
GH & 6 & 966 & 550 & 2.58 & 0.042 \\
OH & 5 & 357 & 157 & & \\
Autumn & & & & & \\
GH & 6 & 1740 & 706 & 3.36 & 0.010 \\
OH & 4 & 505 & 180 & & \\
Winter & & & & & \\
GH & 6 & 1216 & 147 & 15.80 & $\leq 0.001$ \\
OH & 4 & 260 & 8 & & \\
\hline
\end{tabular}

$M V$ mean value, $S D$ standard deviation 
Table 2 Results of the post hoc test (Dunnett T3) to determine differences in home range sizes in hectares (95\% fixed kernel) between the four seasons in the "Glücksburger Heide" $(\mathrm{GH})$ and in the "Oranienbaumer Heide" $(\mathrm{OH})$. ANOVA GH: $\mathrm{F}=3.178, \mathrm{p}=0.046$ and ANOVA $\mathrm{OH}: \mathrm{F}=4.373, \mathrm{p}=0.023$

\begin{tabular}{lllrl}
\hline Study area/time period & $\mathrm{n}$ & \multicolumn{1}{l}{$M D$} & \multicolumn{1}{l}{$S E$} & \multicolumn{1}{l}{$p$} \\
\hline $\mathrm{GH}$ & & & & \\
Spring/Summer & $6 / 6$ & 5151.12 & 231.75 & 0.286 \\
Spring/Autumn & $6 / 6$ & -259.45 & 294.04 & 0.922 \\
Spring/Winter & $6 / 6$ & 265.01 & 82.42 & 0.049 \\
Summer/Autumn & $6 / 6$ & -774.58 & 365.82 & 0.278 \\
Summer/Winter & $6 / 6$ & -250.12 & 232.72 & 0.844 \\
Autumn/Winter & $6 / 6$ & 524.46 & 294.81 & 0.470 \\
OH & & & & \\
Spring/Summer & $5 / 5$ & -119.87 & 71.71 & 0.537 \\
Spring/Autumn & $5 / 4$ & -268.14 & 91.32 & 0.202 \\
Spring/Winter & $5 / 4$ & -23.35 & 13.45 & 0.499 \\
Summer/Autumn & $5 / 4$ & -148.27 & 114.69 & 0.730 \\
Summer/Winter & $5 / 4$ & 96.52 & 70.68 & 0.695 \\
Autumn/Winter & $4 / 4$ & 244.79 & 90.51 & 0.247 \\
\hline
\end{tabular}

$M D$ mean difference between the different seasons, $S E$ standard error. Please note that the mean of the home range size is given in Table 1

\section{Home range overlap}

During the whole year, we had a relatively high percentage of overlap with medians ranging from $61.51 \%$ (summer $\mathrm{OH}$ ) to $96.28 \%$ (winter $\mathrm{GH}$ ) (Fig. 1). We found that the percent of home range overlap varied between seasons and that the overlap for the two herds followed the same seasonal dependence. The overlap percentage was the highest in the winter, with a median value of $96.28 \%$ in the $\mathrm{GH}$ and $95.63 \%$ in $\mathrm{OH}$. During the summer, there was the lowest percentage of spatially overlapping home ranges in both study sites. Furthermore, we found large variations in the home range overlap in the summer; this was most evident in $\mathrm{GH}$, where we found lower percentages and higher percentages next to each other. However, there was only a significant difference between the home range overlap in these sites during the autumn (oneway PERMANOVA: $\mathrm{F}=3.56$; $\mathrm{p}=0.03$; number of permutations =9999) (Fig. 1), with a higher value of overlap in $\mathrm{OH}$.

\section{Space-time-association analysis (Jacob's index)}

We calculated positive values for the Jacob's index for both herds during the whole year. Most values for the Jacob's index were higher in $\mathrm{OH}$ than in $\mathrm{GH}$. We found that only in the summer was there a marginally higher median for GH (Fig. 2). However, we only gained significantly different results for the winter season (one-way PERMANOVA: $\mathrm{F}=16.51 ; \mathrm{p}=0.03$; number of permutations =9999). As with the home range overlap, we found that both herds followed the same seasonal pattern, but the exact values differed. We obtained the lowest values for the Jacob's index for both of the herds in the summer (Fig. 2) and the
Fig. 1 Percentage of home range overlaps in $\mathrm{GH}$ (lower human activity, dark boxplot) and $\mathrm{OH}$ (higher human activity, light boxplot): One-way PERMANOVA showed significant differences in autumn between $\mathrm{GH}$ and $\mathrm{OH}$ (number of permutations $=9999 ; \mathrm{F}=3.56$; $\mathrm{p}=0.03)$. Significant differences are marked with $* \mathrm{p} \leq 0.05$. Boxplot characteristics: Middle $b a r=$ median. Box $=$ first and third quartiles. Whiskers $=$ minimum and maximum (excluding outliers). Smaller symbols are outliers. $\mathrm{n}(\mathrm{GH})=6$ and $\mathrm{n}(\mathrm{OH})=5$ for spring and summer and due to the death of ID2 $4 \mathrm{n}=4$ in autumn and winter (total number of red deer $n=11$ )

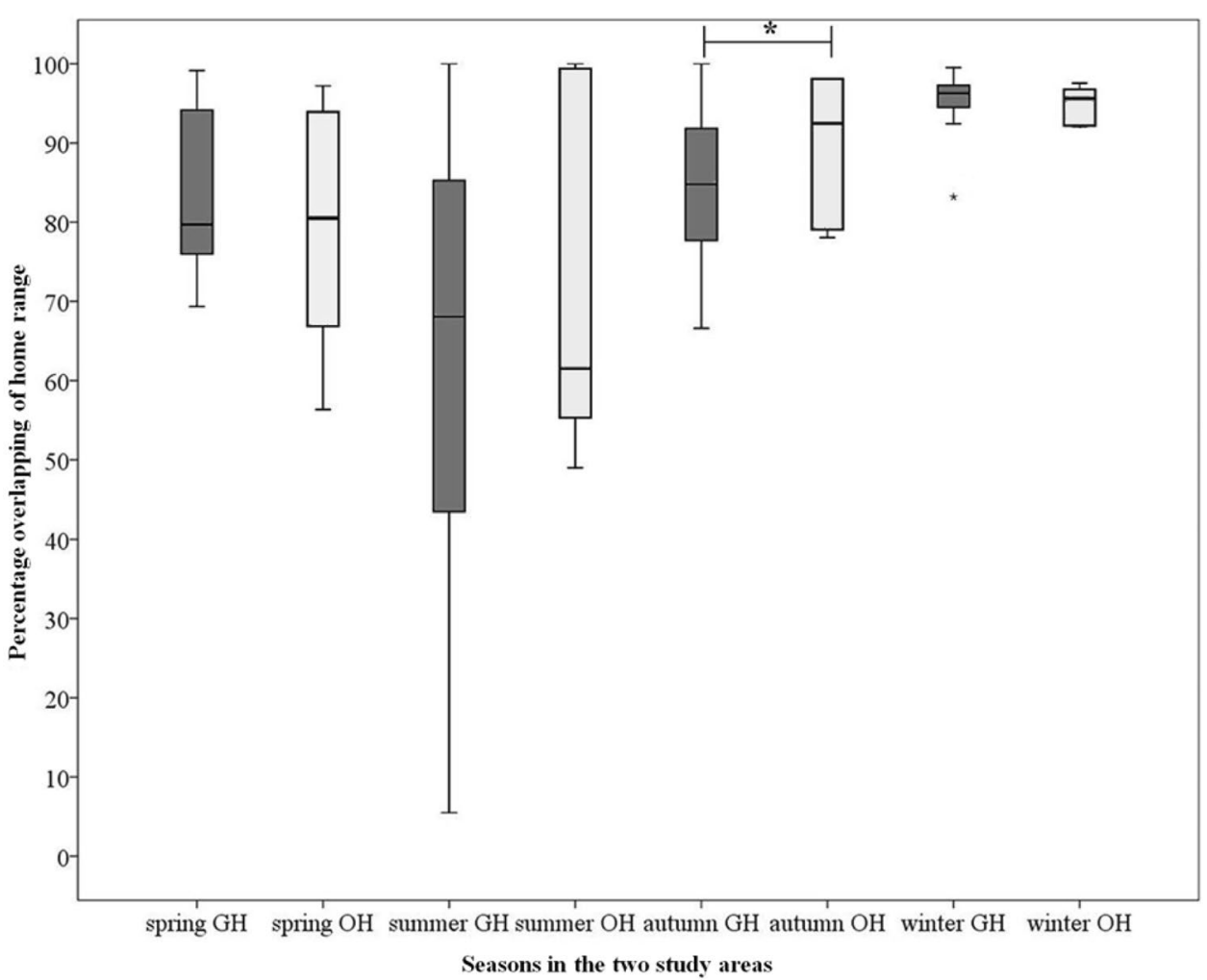


Fig. 2 Space-time-association analysis: comparison of the Jacob's index in GH (lower human activity, dark boxplot) and $\mathrm{OH}$ (higher human activity, light boxplot). One-way PERMANOVA showed significant differences in winter between $\mathrm{GH}$ and $\mathrm{OH}$ (number of permutations $=9999 ; \mathrm{F}=16.51$; $\mathrm{p}=0.03$ ). Significant differences are marked with $* \mathrm{p} \leq 0.05$. Boxplot characteristics: Middle $b a r=$ median. Box $=$ first and third quartiles. Whiskers $=$ minimum and maximum (excluding outliers). Smaller symbols are outliers. $\mathrm{n}(\mathrm{GH})=6$ and $\mathrm{n}(\mathrm{OH})=5$ for spring and summer and due to the death of ID2 $n=4$ in autumn and winter (total number of red deer $\mathrm{n}=11$ )

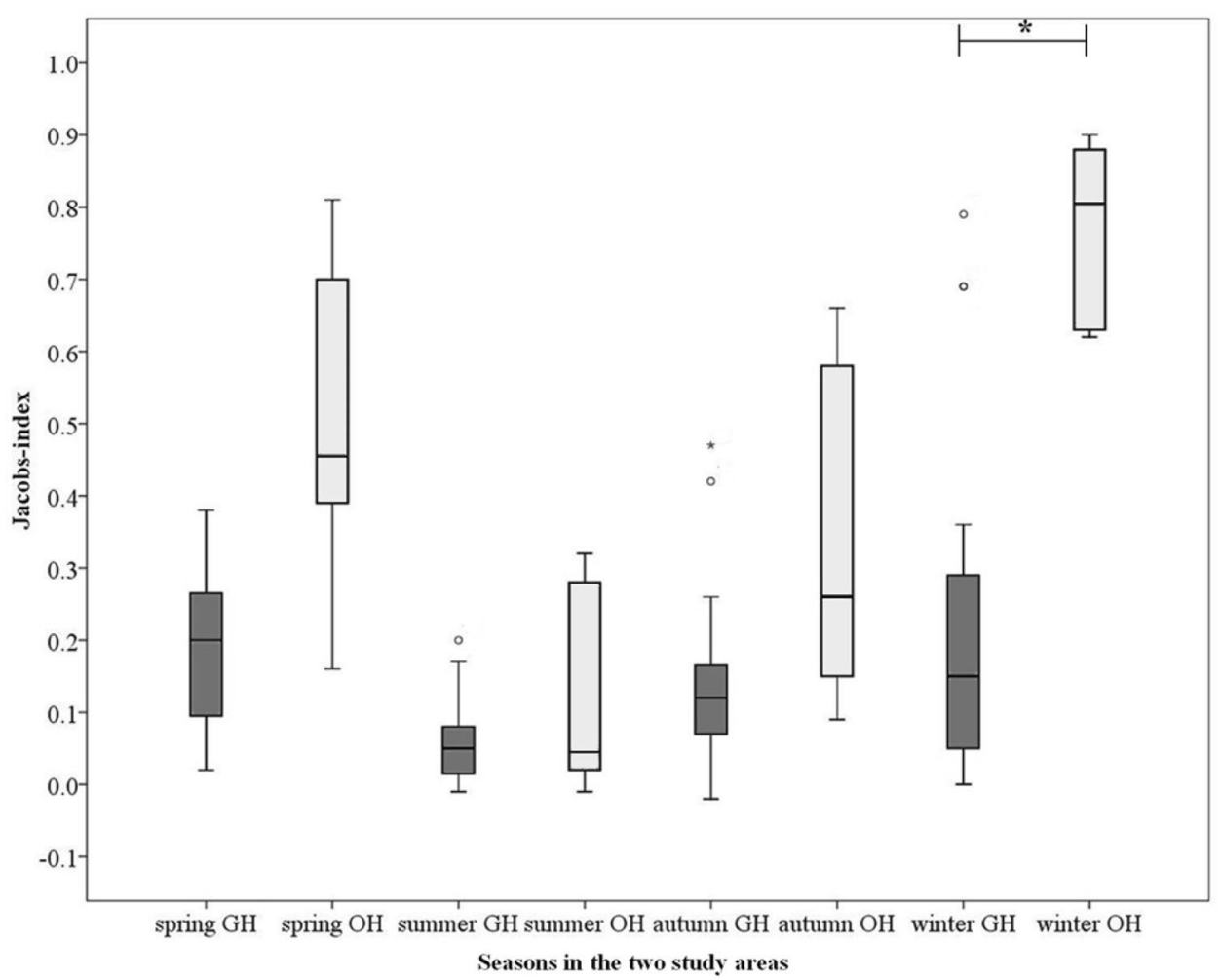

highest median values during the winter in $\mathrm{OH}$ and during the spring in GH. However, the results varied over a large range during the winter in $\mathrm{GH}$ compared to $\mathrm{OH}$. During the spring, the median value of the Jacob's index for both herds was higher than in autumn. This contrasted with the results obtained for overlap of the home range. To visualize the internal dynamic space-time association between the individuals within the herds, we used graphical networks of the Jacob's index (Fig. 3). The networks showed stronger social association between the members of the $\mathrm{OH}$ herd especially during winter (Fig. 3d). Throughout most seasons and in both study areas, we found that the herd may be divided by their level of association. Throughout the seasons, each herd showed to a greater or lesser extent not only three members which associated strongly with the herd, but also members which appeared to be weakly associated (e.g. Fig. 3b, c). Overall, the herd in $\mathrm{OH}$ showed stronger association level than $\mathrm{GH}$, yet this observation was still apparent in $\mathrm{OH}$ during the summer (Fig. 3).

\section{Discussion}

The effects of several factors on the space-time-behaviour, e.g. home range size of deer, have already been investigated (e.g. Said et al. 2005; Rivrud et al. 2010; Coppes et al. 2017; Bojarska et al. 2020), but little is known about the social grouping behaviour of deer, especially of free ranging red deer in a strongly anthropogenous influenced country like Germany. Throughout the last decades, human recreational activities in nature, e.g., biking, hiking and geocaching, have increased strongly in Europe and other continents (Balmford et al. 2009), yet the effects of this on the behaviour of wildlife and the subsequent consequences have not been fully investigated. For example, enhanced flight movements may lead to a higher energy expense by the animals, whereas stronger associations in smaller areas might lead to higher local feeding damage in the forests. To get a better understanding about the impact of human presence on wildlife, we compared the social behaviour of two different herds of red deer from non-migratory populations. We chose two study areas, which have a comparable history of formation, landscape structure, climate, vegetation and wild animal species composition, but differ strongly in anthropogenic influences like human presence. In agreement with our hypothesis, we found that in the area with more human activity, red deer have a significantly smaller home range size and a stronger social space-time-association; however, the results were not significant, except for winter. Although there was one subadult male in the $\mathrm{OH}$ (significant more human activity) herd, we nevertheless assume that it had no major effect on the overall results. According to Clutton-Brook et al. (1982), sub-adults, especially males, have usually a less strong association and keep greater distance to the mother than female 
Fig. 3 Visualized networks of space-time-association (Jacob's Index) from the GH herd (left side, lower human activity) and the $\mathrm{OH}$ herd (right side, higher human activity) through all seasons. The higher the values are for the Jacob's Index, the stronger the association and the darker and wider are the lines between the individuals. The numbers in the networks display unique animal IDs. GH herd details when captured: four female adults (ID 3, 10, 11 and 13), one female sub-adult (ID 9) and one female calf (ID 16). $\mathrm{OH}$ herd details when captured: three female adults (ID 18, 23,

24), one female sub-adult (ID

25) and one male calf (ID 43) a) Spring in $\mathrm{GH}$

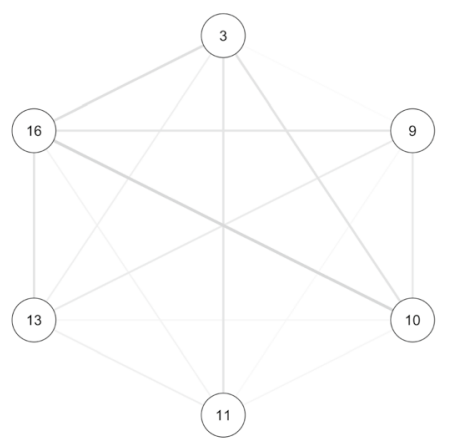

b) Summer in $\mathrm{GH}$

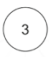

(16)

(13)

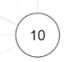

(11)

c) Autumn in GH

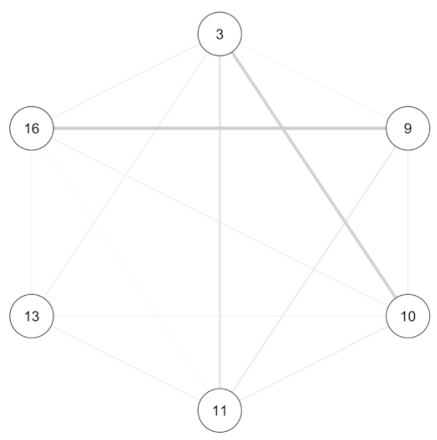

d) Winter in $\mathrm{GH}$

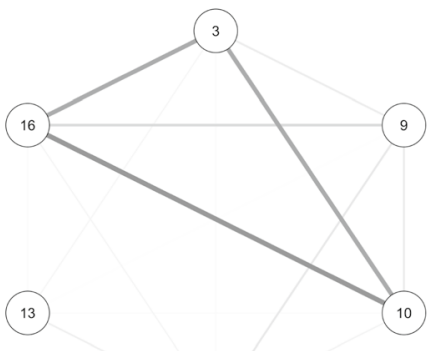

(11)
Spring in $\mathrm{OH}$

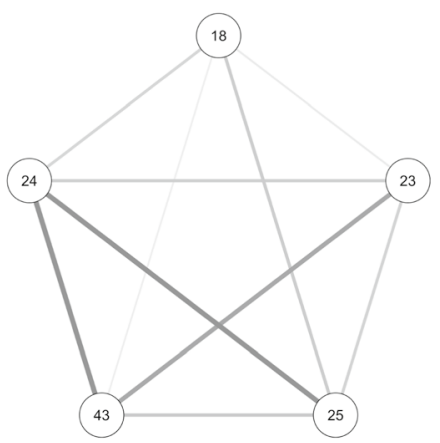

Summer in $\mathrm{OH}$
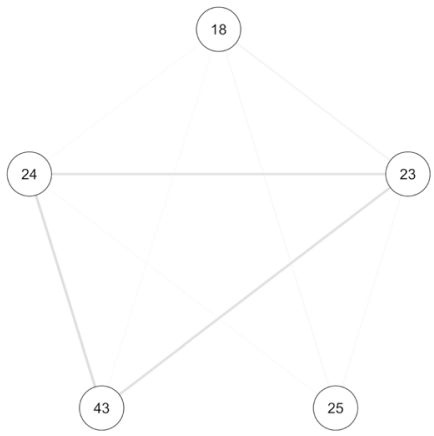

Autumn in $\mathrm{OH}$

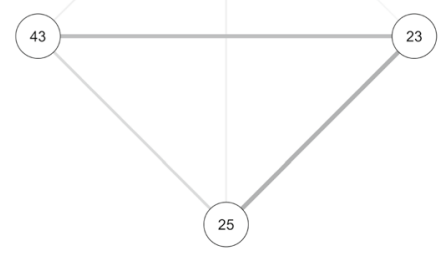

Winter in $\mathrm{OH}$

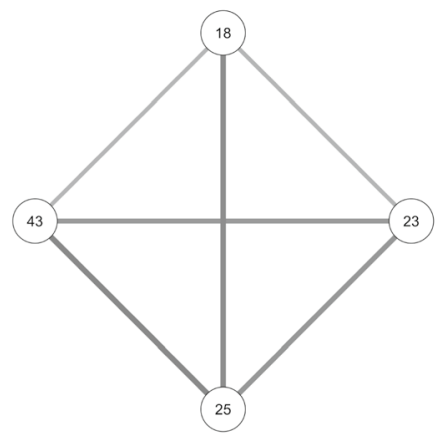


offspring. Many causes have been found and described for the difference in habitat usage and home range size of deer, like the abundance or scarcity of food, climatic factors or rutting season (Tufto et al. 1996; San José and Lovari 1998; Vercauteren and Hygnstrom 1998; Saïd et al. 2005; Rivrud et al. 2010; Reinecke et al. 2014). However, due to the good overall comparability of the study areas, we assume that the significantly smaller home range size can be, in part, ascribed to the higher human activity in $\mathrm{OH}$, which has been discussed by Reinecke et al. (2014) too. Underpinning our results, Nálik et al. (2016) and Picardi et al. (2018) also found a positive relationship between higher human disturbances and less movement of red and roe deer. A decrease in the movement of the deer may be the cause of the smaller home range size found in our study, too. Furthermore, other studies have confirmed the negative effects of anthropogenic influences on the habitat usage and the home range size of deer (Hayes and Krausman 1993; Vercauteren and Hygnstrom 1998; Klemen 2012; Bonnot et al. 2013).

On the other hand, home range size is known to decrease with the increasing population density (Sanderson 1966). This effect has also been found by Kjellander et al. (2004) for territorially living roe deer. In our study, we did not know the general density of red deer in either of the study areas. However, a faecal pellet count was conducted in both study sites. This showed a higher concentration of red deer faeces in GH (227.61 faecal pellets per hectare), the area with the larger home range sizes and less human activity, compared to $\mathrm{OH}$ (77.42 faecal pellets per hectare), the area with the smaller home range sizes and higher human activity (Lehnig 2018). Thus, we assumed that a higher population density cannot be the main reason for a smaller home range size in the $\mathrm{OH}$ study area.

In our study, the home range sizes from red deer varied between the seasons, which also had been discovered by Reinecke et al. (2014). If food availability was the main driver for home range size, we would expect to find the greatest home range sizes in winter like Kamler et al. (2008), but instead, we found the greatest sizes for both areas in autumn, which is known for male deer (Kamler et al. 2008), but was not reported for female red deer.

Our results for the home range overlap showed no clear difference between the two sites. Moreover, we found a large range for the overlap of home ranges in summer in both study areas. Only for autumn did we find a significant higher overlap in $\mathrm{OH}$ (study area with higher human activity) compared to GH. The higher overlap is somehow mirrored by the non-significant results of the other seasons and the space-time-association analyses (Jacob's index), where we found higher mean values for the Jacob's index in OH, although the results were not significantly different, mainly due to a high variability especially in spring and autumn. However, we found a significant result for winter, which was perfectly reflected in the network graph.
The overall higher association behaviour in $\mathrm{OH}$ may reflect the higher human activity in $\mathrm{OH}$ from recreation in the area.

Looking at the seasonal variations, we detected seasonal differences in home range size in both red deer herds. These differences were also found by Clutton-Brock et al. (1982), Luccarini et al. (2006) and by Kamler et al. (2008) but not by Borkowski et al. (2016). In both herds, home range size was largest in autumn, which may be because it was mating season. Similar results were also found by Cederlund and Sand (1994) for moose, but our results were in contrast with a study done by Georgii and Schröder (1983) on red deer in the Bavarian Alps. Lastly, we noted smaller home range sizes in the summer $(\mathrm{GH})$ and spring $(\mathrm{OH})$; this may be related to natal and lactation time (Bertrand et al. 1996). Concerning the effects of seasons on the spatial overlap of home ranges, and the results of the space-time-association analyses, we identified the same seasonal dependent pattern in both of the research areas. We found the lowest home range overlap and space-time-association during the summer period. In winter, we found the largest home range overlap for both study sites. Similarly, in $\mathrm{OH}$, we found the strongest space-time-association during the winter, but for $\mathrm{GH}$, we found the strongest association during the spring. This kind of aggregation in late winter and spring, also mirrored in our visualized network graphs, was also documented by Hawkins and Klinstra (1970) for female white-tailed deer. Likewise, Jedrzejewski et al. (2006) found evidence of stronger grouping behaviour for red deer during the winter. The biggest effect on grouping behaviour in the study of Jedrzejewski et al. (2006) was also ascribed to human disturbance.

Furthermore, we found a high distinct variability in the results of the home range overlap in the summer in both areas. This variability may be related to calving time when the group structure typically dissolves in preparation for parturition, as found for white-tailed deer (Bertrand et al. 1996). This was reflected by a low Jacob's index (index for space-time-association) in the summer season. The high variability in Jacob's index in the winter in GH due to outliers may be connected to the two driven hunts, which may have caused a temporal change in association of the herd.

Considering that the individuals of the herd were captured together and that they are of mostly simultaneous itinerate nature throughout the whole year, we assumed a relatively high degree of kinship for both herds. However, a genetic relationship study would be useful to make more accurate statements, as the degree of kinship can influence the social interaction of deer (Walrath et al. 2011; Magle et al. 2013). One drawback for our study was the very small sample sizes, which increased the risk of the results not being representative for the areas. Further long-term research, with more herds and study sites to compare (as individuals within the same herd represent dependent replicates), is essential to 
fully understand the dynamics of the association behaviour within herds and to verify and enhance our results.

Recapitulated, the herd with more exposure to human activities resulted in a significantly overall smaller home range size during all seasons and higher values for the space-time-association index (significantly in winter). Future studies with a larger sample size are needed to understand the consequences of our findings (smaller home ranges and higher association between animals) on the forest and habitat utilization.

Acknowledgements The results are part of the project "Influence of big scale conservation grazing projects on space-time behavior of red deer (Cervus elaphus) on selected DBU Heritage areas," which was funded by the DBU Natural Heritage branch, Naturerbe GmbH. We are very grateful to the DBU Natural Heritage for providing us with the data and to Alexander Martini, Egbert Gleich and all the employees of the federal forest for their support in fieldwork. Furthermore, we are indebted to Julian Glos for his help with statistical analyses.

Funding Open Access funding enabled and organized by Projekt DEAL. DBU Natural Heritage branch, Naturerbe GmbH.

Open Access This article is licensed under a Creative Commons Attribution 4.0 International License, which permits use, sharing, adaptation, distribution and reproduction in any medium or format, as long as you give appropriate credit to the original author(s) and the source, provide a link to the Creative Commons licence, and indicate if changes were made. The images or other third party material in this article are included in the article's Creative Commons licence, unless indicated otherwise in a credit line to the material. If material is not included in the article's Creative Commons licence and your intended use is not permitted by statutory regulation or exceeds the permitted use, you will need to obtain permission directly from the copyright holder. To view a copy of this licence, visit http://creativecommons.org/licenses/by/4.0/.

\section{References}

Allee WC (1931) Animal aggregations. University of Chicago Press, Chicago

Balmford A, Beresford J, Green J, Naidoo R, Walpole M, Manica A (2009) A global perspective on trends in nature-based tourism. PLoS Biol 7(6):e1000144. https://doi.org/10.1371/journal.pbio. 1000144

Berger J (2007) Fear, human shields and the redistribution of prey and predators in protected areas. Biol Lett 3:620-623. https://doi.org/ 10.1098/rsbl.2007.0415

Bertrand MR, Denicola AJ, Beissinger SR, Swihart RK (1996) Effects of parturition on home ranges and social affiliations of female white-tailed deer. J Wildl Manage 60:899-909. https://doi.org/ $10.2307 / 3802391$

Bojarska K, Kurek K, Śnieżko S, Król W, Baś G, Wierzbowska I, Widera E, Okarma H, Zyśk-Gorczyńska E (2020) Winter severity and anthropogenic factors affect spatial behaviour of red deer in the Carpathians. Mamm Res 65:815-823. https://doi.org/10.1007/ s13364-020-00520-z

Bonnot N, Morellet M, Verheyden H, Cargnelutti B, Lourtet B, Klein F, Hewison MAJ (2013) Habitat use under predation risk: hunting, roads and human dwellings influence the spatial behaviour of roe deer. Eur J Wildl Res 59:185-193. https://doi.org/10. 1007/s10344-012-0665-8

Borkowski J, Ukalska J, Jurkiewicz J, Checko E (2016) Living on the boundary of a post-disturbance forest area: the negative influence of security cover on red deer home range size. Forest Ecol Manag 381:247-257. https://doi.org/10.1016/j.foreco.2016.09.009

Cederlund G, Sand H (1994) Home-range size in relation to age and sex in moose. J Mammal 75:1005-1012. https://doi.org/10.2307/ 1382483

Clutton-Brock TH, Guinness FE, Albon SD (1982) Red deer: behavior and ecology of two sexes. University of Chicago Press, Chicago

Coppes J, Burghardt F, Hagen R, Suchant R, Braunisch V (2017) Human reaction affects spatio-temporal habitat use patterns in red deer (Cervus elaphus). PLoS ONE 12:e0175134. https://doi. org/10.1371/journal.pone.0175134

Croft DP, James R, Krause J (2008) Exploring animal social networks. Princeton University Press, New Jersey

Csardi G, Nepusz T (2006) The igraph software package for complex network research, InterJournal, Complex Systems 1695

Darling FF (1937) A herd of red deer. Oxford University Press, London

Doncaster CP (1990) Non parametric estimates of interaction from radio-tracking data. J Theor Biol 143:431-443. https://doi.org/ 10.1016/S0022-5193(05)80020-7

Dunn JE (1979) A complete test for dynamic territorial interaction. Proceedings of the Second International Conference on Wildlife Biotelemetry. 159-169. University of Wyoming, Laramie, Wyoming.

Edge WD, Marcum CL, Olson SL (1985) Effects of logging activities on home-range fidelity of elk. J Wildl Manage 49:741-744. https://doi.org/10.2307/3801704

Georgii B, Schröder W (1983) Home range and activity patterns of male red deer (Cervus elaphus L.) in the Alps. Oecol 58:238-248. https://doi.org/10.1007/BF00399224

Gillich B, Michler FU, Stolter C, Rieger S (2016) Red deer - living on pastures? Study on space-time-behavior of red deer depending on grazing projects. Wildbiologische Forschungsberichte. Große Pflanzenfresser, Große Karnivoren, Große Schutzgebiete (2016 in Trippstadt). Schriftenreihe der Vereinigung der Wildbiologen und Jagdwissenschaftler Deutschlands (VWJD) Band 2. ISBN:978-3-945941-16-4

Grund MD, McAninch JB, Wiggers EP (2002) Seasonal movements and habitat use of female white-tailed deer associated with an urban park. J Wildl Manage 66:123-130. https://doi.org/10.2307/ 3802878

Hall MJ (1983) Social organization in an enclosed group of red deer (Cervus elaphus L.) on Rhum. I. The dominance hierarchy of females and their offspring. Z Tierpsychol 61:250-262. https:// doi.org/10.1111/j.1439-0310.1983.tb01341.x

Hammer Ø, Harper DAT, Ryan PD (2001) PAST: Paleontological Statistic software package for education and data analysis. Palaeontol Electron 4:1-9

Hawkins RE, Klimstra WD (1970) A preliminary study of the social organization of white-tailed deer. J Wildl Manage 34:407-419. https://doi.org/10.2307/3799027

Hayes CL, Krausman PR (1993) Nocturnal activity of female desert mule deer. J Wildl Manage 57:897-904. https://doi.org/10.2307/ 3809095

Hirth DH (1977) Social behavior of white-tailed deer in relation to habitat. Wildl Monogr 53:3-55. http://www.jstor.org/stable/3830446

Jayakody S, Sibbald AM, Gordon IJ, Lambin X (2008) Red deer Cervus elephus vigilance behaviour differs with habitat and type of human disturbance. Wildl Biol 14:81-91. https://doi.org/10.2981/09096396(2008)14[81:RDCEVB]2.0.CO;2

Jedrzejewski W, Spaedtke H, Kamler JF, Jedrzejewska B, Stenkewitz U (2006) Group size dynamics of red deer in Bialowieza primeval 
forest. Poland J Wildl Manage 70:1054-1059. https://doi.org/10. 2193/0022-541X(2006)70[1054:GSDORD]2.0.CO;2

Jentzsch M, Reichhoff L (2013) Handbuch der Fauna-Flora-Habitat-Gebiete Sachsen-Anhalts. Landesamt für Umweltschutz Sachsen-Anhalt, Halle (Saale)

Jerina, K (2012) Roads and supplemental feeding affect home-range size of Slovenian red deer more than natural factors. J Mammal 93:1139-1148. https://doi.org/10.1644/11-MAMM-A-136.1

Kamler JF, Jedrzejewski W, Jedrzejewska B (2008) Home ranges of red deer in a European old-growth forest. Am Midl Nat 159:75-82. https://doi.org/10.1674/0003-0031(2008)159[75: HRORDI]2.0.CO;2

Kaulhala K, Holmala K (2006) Contact rate and risk of rabies spread between medium-sized carnivores in southeast Finland. Ann Zool Fenn 43: 348-357. ISSN 0003-455X

Kenward RE (2001) A manual for wildlife radio tagging. Academic Press, London

Kenward RE, Clarke RT, Hodder KH (2001) Density and linkage estimators of home range: defining multi-nuclear cores by nearest-neighbor clustering. Ecology 82:1905-1920. https://doi.org/ 10.1890/0012-9658(2001)082[1905:DALEOH]2.0.CO;2

Kenward RE, Casey NM, Walls SS, South AB (2014) Ranges 9: for the analysis of tracking and location data. Online manual. Anatrack Ltd, Wareham

Kjellander P, Hewison AJM, Liberg O, Angibault J-M, Bideau E, Cargnelutti B (2004) Experimental evidence for densitydependence of home-range size in roe deer (Capreolus capreolus L.): a comparison of two long-term studies. Oecol 139:478-485. https://doi.org/10.1007/s00442-004-1529-z

Klemen J (2012) Roads, supplemental feeding affect home-range size of Slovenian red deer more than natural factor. J Mammal 93:1139-1148. https://doi.org/10.1644/11-MAMM-A-136.1

Krause J, Godin JGJ (1995) Predator preferences for attacking particular prey group sizes: consequences for predator hunting success and prey predation risk. Anim Behav 50:465-473. https://doi.org/ 10.1006/anbe. 1995.0260

Krause J, Ruxton GD, Rubenstein D (1998) Is there always an influence of shoal size on predator hunting success? J Fish Biol 52:494-501. https://doi.org/10.1111/j.1095-8649.1998.tb02012.x

Landesamt für Umweltschutz SachsenAnhalt and Wolfskompentenzzentrum Iden (2017) Wolfsmonitoring SachsenAnhalt Bericht zum Monitoringjahr 2016/2017.

Lazarus J (1979) The early warning function of flocking in birds: an experimental study with captive quelea. Anim Behav 27:855-865. https://doi.org/10.1016/0003-3472(79)90023-X

Lehnig A (2018) Schalenwild in Glücksburger Heide und Oranienbaumer Heide - Erfassung von Aufenthaltsschwerpunkten mittels einer Losungskartierung und Vergleich der beiden Untersuchungsgebiete. University of Applied Sciences, Eberswalde, Bachelor-Thesis

Lone K, Loe LE, Meisingset EL, Stamnes I, Mysterud A (2015) An adaptive behavioural response to hunting: surviving male red deer shift habitat at the onset of the hunting season. Anim Behav 102:127-138. https://doi.org/10.1016/j.anbehav.2015.01.012

Luccarini S, Mauri L, Ciuti S, Lamberti P, Apollonio M (2006) Red deer (Cervus elaphus) spatial use in the Italian Alps: home range patterns, seasonal migrations, and effects of snow and winter feeding. Ethol Ecol Evol 18:127-145. https://doi.org/10.1080/08927014. 2006.9522718

MacDonald DW (1983) The ecology of carnivore social behavior. Nature 301:379-384. https://doi.org/10.1038/301379a0

MacNulty DR, Tallian A, Stahler DR, Smith DW (2014) Influence of group size on the success of wolves hunting bison. PLoS ONE 9:e112884. https://doi.org/10.1371/journal.pone. 0112884

Magle SB, Samuel MD, Van Deelen TR, Robinson SJ, Mathews NE (2013) Evaluating spatial overlap and relatedness of white-tailed deer in a chronic wasting disease management zone. PLoS ONE 8:e56568. https://doi.org/10.1371/journal.pone.0056568

Michler FU (2016) Säugetierkundliche Freilandforschung zur Populationsbiologie des Waschbären Procyon lotor in einem naturnahen Tieflandbuchenwald im Müritz-Nationalpark (Mecklenburg-Vorpommern). Dissertation, University of Technology Dresden

Minta SC (1992) Tests of spatial and temporal interaction among animals. Ecol Appl 2:178-188. https://doi.org/10.2307/1941774

Nálik A, Sándor G, Tari T, Heffenträger G, Pócza G (2016) Factors affecting diurnal activity of red deer. Conference paper. 5th International Hunting and Game Management Symposium 10-12.11.2016. Debrecen

Nelson ME, Mech LD (1981) Deer social organization and wolf predation in northeastern Minnesota. Wildl Monogr 77:3-53. http://www.jstor.org/stable/3830578

Picardi S, Basille M, Peters W, Ponciano JM, Boitani L, Cagnacci F (2018) Movement responses of roe deer to hunting risk. J Wildl Manage 83:43-51. https://doi.org/10.1002/jwmg.21576

R Core Team (2013) R: A language and environment for statistical computing. R Foundation for Statistical Computing, Vienna, Austria. URL http://www.R-project.org

Reinecke H, Leinen L, Thißen I, Meißner M, Herzog S, Schütz S, Kiffner C (2014) Home range size estimates of red deer in Germany: environmental, individual and methodological correlates. Eur J Wildl Res 60:237-247. https://doi.org/10.1007/ s10344-013-0772-1

Rivrud IM, Loe LE, Mysterud A (2010) How does local weather predict red deer home range size at different temporal scales? J Anim Ecol 79:1280-1295. https://doi.org/10.1111/j.1365-2656. 2010.01731.x

Saïd S, Gaillard J-M, Duncan P, Guillon N, Guillon N, Servanty S, Pellerin M, Lefeuvre K, Martin C, Van Laere G (2005) Ecological correlates of home-range size in spring-summer for female roe deer (Capreolus capreolus) in a deciduous woodland. J Zool 267:301-308. https://doi.org/10.1017/S0952836905007454

Said S, Servanty S (2005) The influence of landscape structure on female roe deer home-range size. Landsc Ecol 20:1003-1012. https://doi.org/10.1007/s10980-005-7518-8

Sanderson GC (1966) The study of mammal movements: a review. J Wildl Manage 30:215-235. https://doi.org/10.2307/3797914

San José C, Lovari S (1998) Ranging movements of female roe deer: do home-loving does roam to mate? Ethology 104:721-728. https://doi.org/10.1111/j.1439-0310.1998.tb00106.x

Scholten J, Moe SR, Hegland SJ (2018) Red deer (Cervus elaphus) avoid mountain biking trails. Eur J Wildl Res 64:8. https://doi. org/10.1007/s10344-018-1169-y

Seip DR, Johnson CJ, Watts GS (2007) Displacement of mountain caribou from winter habitat by snowmobiles. J Wildl Manage 71:1539-1544. https://doi.org/10.2193/2006-387

Sibbald AM, Hooper RJ, McLeod JE, Gordon IJ (2011) Responses of red deer (Cervus elaphus) to regular disturbance by hill walkers. Eur J Wildl Res 57:817-825. https://doi.org/10.1007/ s10344-011-0493-2

Signer J, Balkenhol N (2015) Reproducible home ranges ( $r h r)$ : a new, user-friendly R package for analyses of wildlife telemetry data. Wildl Soc Bull 39:358-363. https://doi.org/10.1002/wsb.539

Silverman BW (1986) Density estimation for statistics and data analysis. Chapman \& Hall, London

SPSS Inc. (2008) SPSS Statistics for Windows, Version 17.0. Chicago: SPSS Inc.

Stankowich T (2008) Ungulate flight responses to human disturbance: a review and meta-analysis. Biol Conserv 141:2159_ 2173. https://doi.org/10.1016/j.biocon.2008.06.026

Tufto J, Andersen R, Linnell J (1996) Habitat use and ecological correlates of home range size in a small cervid: the roe deer. J Anim Ecol 65:715-724. https://doi.org/10.2307/5670 
Vercauteren KC, Hygnstrom SE (1998) Effects of agricultural activities and hunting on home ranges of female white-tailed deer. J Wildl Manage 62:280-285. https://doi.org/10.2307/3802289

Walrath R, Van Deelen TR, Vercauteren KC (2011) Efficacy of proximity loggers for detection of contacts between maternal pairs of white-tailed deer. Wildl Soc Bull 35:452-460. https://doi.org/10.1002/wsb.76
Worton BJ (1989) Kernel methods for estimating the utilization distribution in home-range studies. Ecology 70:164-168. https://doi. org/10.2307/1938423

Publisher's Note Springer Nature remains neutral with regard to jurisdictional claims in published maps and institutional affiliations. 